\title{
A city in liquid modernity: a sociological perspective
}

\author{
Edyta Barańska \\ Institute of Sociology, University of Marii Curie-Sklodowskiej \\ edytkabaranska@gmail.com
}

\section{Keywords: culture, a city, liquid modernity, postmodernity, Zygmunt Bauman, sociology of culture postmodern city}

\begin{abstract}
:
Western culture grew out of conviction about the social nature of man. It is based on the assumption that man is a social being, that he is a resident of the city. The most unpleasant image for an ancient man was the prospect of living outside the city, being excluded from its borders. The city is like a way of being, an expression of our social way of existence. Aristotle spoke of human nature, that its embodiment is a polis. This community life builds human identity. Such an image of a human being, as a creature entangled in the city space, is still valid today. Until recently Hannah Arendt wrote that our human condition is to participate in public space, that human life is humanized in our community, it defines our being as human. Today, however, the concept of the city has changed and the concept of space has taken on a different meaning. The city is not something stable and unchanging, on the contrary - today it is in constant motion, its feature is its liquidity. The feature of city residents is mobility and absolute freedom of movement. Our imaginations of space and boundaries, the understanding of what is local and global have changed. The world of borders has been replaced with our idea of the transparency of the city - nowadays one can not hide anymore. Under the influence of many socio-economic changes, the emergence of new forms of communication, the city has changed not only its physical form, but - above all - our human condition. It ceased to provide us with a sense of security and the ability to identify, but threw into an area of boundless possibilities. This dynamics of changes also reflects the way of describing the city: a map that served premoderns to describe the geographical city, in the modern world it has to be a grid that imposes itself on the city plan. This physical distribution of the city is now to be subordinated and adapted to the spatial plan of the city - this is the vision of a perfect, utopian and happy modern city. Modernity, says Zygmunt Bauman, does not just want to describe what is, but to map and impose space on the map. Today, we have got rid of this utopian idea of ordering according to our own plan. Under the influence of changes, we have become residents of space without borders. Bauman, this our way of being today, describes as liquidity. Does this mean, however, that we have lost the foundations of our human lives that have defined us as people? Is this shrinkaging of the city space and the lack of a city street an embodiment of our new contemporary condition? Perhaps today's city no longer belongs to the inhabitants of polis, but to the invaders? Perhaps the city's inhabitants will be permanently accompanied by the urban fear of lack of domicile. The aim of my speech is to show what changes accompany the city and us as residents of the city as well as to present the cultural consequences of these changes.
\end{abstract}

